\title{
DO DISCURSO POLÍTICO ÀS NOVAS TECNOLOGIAS um percurso sobre o objeto de estudo da Análise do Discurso
}

\author{
Evandra Grigoletto
}

RESUMO: Ce travail présente une réflexion sur le trajet théorique tracé par Pêcheux, de 1969 à 1983, sur l'objet d'étude de l'Analyse du Discours, ainsi que sur les déplacements que cet objet a expérimenté face au développement de cette théorie au Brésil. Sont considerés ici de nouveaux langages et, par conséquent, des discoursivités nouvelles. Pour lês examiner, j'élis le discours pédagogique qui circule dans les Ambiances Virtuelles d'Apprentissage (AVAs), dont je présente une brève analyse dans laquelle je discute ce qui a changé dans le fonctionnement de ce discours, en rélation au discours pédagogique traditionnel.

PALAVRAS-CHAVE: discurso político, novas tecnologias, novas discursividades, discurso pedagógico, ambientes virtuais de aprendizagem.

\section{SITUANDO A REFLEXÃO}

Seria estranho que os analistas do discurso fossem os últimos a saber sobre a conjunção existente entre a cegueira da história e a surdez da língua que diz respeito, ao mesmo tempo, a seus objetos e a suas práticas. Já era hora de começar a quebrar os espelhos (PÊCHEUX, 2009, p.26¹)

Considerando os vinte anos (1969-2009) já completados do aparecimento dos primeiros escritos de Pêcheux e, com eles, o surgimento de uma teoria que vinha romper com os pressupostos estruturalistas até então predominantes nos estudos linguísticos e propunha um novo objeto de estudo - o discurso -, o objetivo deste artigo é resgatar um pouco dessa história já construída na Análise do Discurso, focalizando o nosso olhar para, justamente, o objeto de estudo desta teoria: o discurso. Objeto este que, como diz Pêcheux na epígrafe acima, leva os analistas, trabalhando com materialidades que são próprias das práticas e objetos da língua e da história, a romper com a cegueira da história e a surdez da língua.

Para dar conta desse objetivo maior, reflito, num primeiro momento, sobre o percurso teórico traçado por Pêcheux, de 1969 a 1983, acerca do objeto de estudo da Análise do Discurso ou, melhor dizendo, acerca dos corpora que serviram de materialidade para análise dos trabalhos, em Análise do Discurso, realizados na França nesse período. Em seguida, apresento brevemente a ampliação desse corpora nos trabalhos que vêm sendo realizado em Análise do Discurso, especialmente aqui no

\footnotetext{
Professora adjunta do Departamento de Letras da Universidade Federal de Pernambuco.

Esse texto, originalmente, foi publicado na França, em 1981, como prefácio do livro "Analyse du discours politique", de Jean-Jacques Courtine. A citação aqui foi retirada da tradução feita por Bacharéis em Letras pela Universidade Federal do Rio Grande do Sul, sob a supervisão da prof ${ }^{a}$ Patrícia Chittoni Ramos Reuillard, e publicação pela editora da UFSCAR, em 2009.
} 
Brasil, a partir das demandas que a sociedade contemporânea tem nos apresentado em termos de novas linguagens e, por sua vez, de novas discursividades.

Por fim, para aprofundar a reflexão acerca dessas novas discursividades, apresento uma breve análise de uma materialidade ainda em "estado de corpus", retomando as palavras de Maldidier (2003), sustentada por/num "velho" discurso: o pedagógico. Refiro-me ao discurso pedagógico apresentado nas disciplinas dos cursos de Ensino a Distância que surgiram nas Universidades Públicas Brasileiras, a partir de 2005, com a criação do Sistema Universidade Aberta do Brasil (UAB).

PERSEGUINDO A REFLEXÃO TEÓRICA ACERCA DAS DIFERENTES MATERIALIDADES: DE PÊCHEUX A AUTORES BRASILEIROS

Mais do que falar do objeto de estudo da Análise do Discurso (AD), que continua sendo o mesmo nesses vintes anos de história/memória da/na $\mathrm{AD}$, pretendo refletir sobre a heterogeneidade desse objeto, apontando as diferentes materialidades discursivas que sedimentaram, fizeram e continuam fazendo parte dessa história, construindo uma memória para esse campo teórico no interior dos estudos da linguagem.

E, para refletir sobre a heterogeneidade que atravessa o objeto discurso, é preciso iniciar por Pêcheux, o precursor da Análise do Discurso. Retomo, então, de forma muito breve, alguns textos do próprio Pêcheux, mas também de outros autores, como Denise Maldidier e Francine Mazière que ajudaram a construir/a escrever a história da AD na França, tal como formulada pelo mestre Pêcheux.

Em 1969, quando Pêcheux lança o texto L'analyse automatique du discours, conhecido como texto fundador da ADD, a sua preocupação era com a construção de uma "máquina de ler", cujo objeto de análise estava centrado no discurso político. Nesse texto se ligam, segundo Maldidier (2003, p.19) "todos os fios constitutivos de um objeto radicalmente novo: o discurso", que sempre foi e continuando sendo o objeto de estudo da Análise do Discurso. Criticando o esquema informacional de Jakobson e, por sua vez, rejeitando "a mensagem como transmissão de informação", Pêcheux vai formular, nessa obra, sua primeira noção de discurso, "que implica que não se trata necessariamente de uma transmissão de informação entre A e B, mas, de modo mais geral, de um "efeito de sentido" entre os pontos A e B" (PÊCHEUX, 1997, p.82)2. Daí a definição de discurso como efeito de sentido entre interlocutores, o que significa dizer que o que importa, na produção de sentido, é a posição ocupada na estrutura de uma formação social por A e B, que "designam algo diferente da presença física de organismos humanos individuais" (op. cit). O sentido, então, não está nem em A nem em B, mas na relação estabelecida entre eles, considerando os lugares ocupados socialmente por esses sujeitos e as determinações daí decorrentes para a produção de sentido.

Portanto, o discurso, como vimos acima, desde os primeiros escritos de Pêcheux, "deve ser tomado como um conceito que não se confunde nem com o discurso empírico sustentado por um sujeito nem com o texto, um conceito que estoura qualquer concepção comunicacional da linguagem" (MALDIDIER, 2003, p.21). Assim, o discurso, enquanto objeto de estudo, não muda; o que se apresenta como novo, como desafio para o analista romper com a cegueira da história e a surdez da língua são as

\footnotetext{
2 A data aqui, bem como de outras citações do autor ao longo do texto, referem-se às edições brasileiras consultadas das
} obras de Pêcheux. 
novas materialidades/linguagens que constituem os discursos. A elaboração, proposta por Pêcheux nessa época, de uma análise automática remete, a "um dispositivo técnico complexo informatizado", que "se inscreve em sua reflexão de então sobre as práticas e os instrumentos científicos" (MALDIDIER, 2003, p.20). Esse dispositivo deveria dar conta da leitura dos "processos discursivos" e, por sua vez, dos efeitos de sentidos produzidos a partir desses processos, tomando como base as "condições de produção" dos discursos. A noção de condições de produção, cunhada nesse primeiro momento da teoria por Pêcheux, foi (e continua sendo) fundamental para inscrever o objeto de estudo da AD no "tecido histórico-social" (op. cit, p.23).

Na AAD-69, o corpus constituía um espaço fechado, e o domínio de análise estava centrado no discurso político, como já referi. A análise de cada sequência discursiva, escreveu mais tarde o próprio Pêcheux (1983), era "considerada uma operação autônoma, um pré-requisito indispensável para a análise discursiva do corpus" (PÊCHEUX, 1997, p.312), o que era regulado por "condições de produção estáveis e homogêneas". Por isso, a análise do corpus consistia principalmente "em detectar e em construir sítios de identidade parafrásticas interseqüenciais" (Idem, ibidem)

No entanto, essa máquina discursiva de ler, proposta por Pêcheux em 1969, não tem, segundo Maldidier, nada da máquina universal esperada desde sempre pelos tecnocratas. "Trata-se antes, segundo a expressão de Althusser, de "mudar de terreno", apoiando-se sobre a lingüística e a informática, sem fazer delas simples ferramentas." (MALDIDIER, 2003, p.24)

$\mathrm{Na}$ fase que compreende o que Pêcheux chamou, em seu texto $A$ análise de discurso: três épocas, a AD-2, as relações entre as "máquinas" discursivas estruturais se tornam o objeto da AD. Trata-se de "relações de forças desiguais" entre processos discursivos. Surge a noção de Formação Discursiva, que começa a fazer explodir a noção de máquina estrutural fechada (PÊCHEUX, 1997, p.314). E também a noção de interdiscurso, que foi o conceito, segundo Maldidier (2003), mais fundamental de toda a construção teórica de Pêcheux. É nessa época também que Pêcheux publica, nas palavras de Maldidier, seu "grande livro" - Semântica e Discurso - onde "ele apresenta o estado mais acabado da teoria" (...). "O discurso é a figura central do livro. Ele liga todos os fios: da lingüística e da história, do sujeito e da ideologia, da ciência e da política." (MALDIDIER, 2003, p. 37, p.45). A construção desse arcabouço teórico em torno do discurso produz, segundo o próprio Pêcheux, um deslocamento da AD-2 "ao nível da construção dos corpora discursivos, que permitem trabalhar sistematicamente suas influências internas desiguais, ultrapassando o nível da justaposição contrastada." (PÊCHEUX, 1997, p.315)

A aproximação/o diálogo da teoria do discurso com historiadores, como Régine Robin, promove, como bem pontua Mazière, "a passagem de um corpus agenciado pelos conhecimentos prévios do analista a um corpus construído, de modo ainda mais erudito, por um "projeto temático" no arquivo, depois à noção de "configuração", por definição dinâmica e instável." (MAZIÈRE, 2007, p.24).

E essa passagem de corpus exige a emergência de novos procedimentos, através da desconstrução das maquinarias discursivas. Fase essa que Pêcheux intitulou a AD-3, a qual leva até "o limite a crise da noção de máquina discursiva estrutural." (PÊCHEUX, 1997, p.315). Dessa forma, o procedimento da AD por etapas, com ordem fixa, explode definitivamente.

Os inícios dos anos 80 marcam uma nova etapa na $\mathrm{AD}$. A pesquisa, que envolvia sempre questões de leitura, se dá, a partir desse momento, no "confronto com os textos 
sócio-históricos mais diversos" (MALDIDIER, 2003, p.80), o que significa uma ampliação do corpus de pesquisa, que não se restringia mais somente aos discursos escritos-oficiais (entre eles o discurso político), mas ampliava-se à análise dos discursos orais do cotidiano. Aparece também, nessa época, o termo discursividade ${ }^{3}$, no colóquio Materialités Discursives, o que apontava, segundo Maldidier (2003, p.94), para um novo horizonte de trabalho.

Nessa fase, Pêcheux escreve textos fundamentais que orientam os novos procedimentos teóricos metodológicos da AD (Discurso: estrutura ou acontecimento; Informática e Análise de Discurso; Leitura e Memória: projeto de pesquisa; Análise de Discurso: três épocas; Ler o Arquivo Hoje; O estranho espelho da Análise do Discurso - prefácio da tese de Courtine). Segundo Mazière, "da facilidade metodológica oferecida por um corpus construído como conjunto de dados prévios, feito do discurso doutrinal contrastado, produto de condições de produção controláveis e tomado em um ritual bem particular, passamos a procedimentos de construção de seqüências discursivas ligadas a uma "rede de memória", segundo o termo de Courtine." (MAZIĖRE, 2007, p.59). O corpus não é mais dado a priori, mas construído, a partir de um arquivo, de forma dinâmica e com base no foco de análise. Surge, então, a expressão "estado de corpus", cunhada por Guilhaumou e Maldidier. E trata-se de um estado de corpus porque ele pode mudar durante a análise, abrir-se para novas interpretações. Essa rede de memória deverá, no curso da escrita da análise, conforme pontua Mazière,

construir novos enunciados abrindo novas regiões de corpus.(...) Por fim, o corpus não é mais um conjunto estanque de textos, é um conjunto sem fronteiras no qual o interdiscurso, exterior, irrompe no intradiscurso. Sua construção supõe renunciar ao sonho de uma interpretação fechada garantida por uma leitura explicitada em proveito de uma leitura-escrita e de uma "política de interpretação" que se basearia na avaliação das "formas de interpretação" em uma conjuntura. (MAZIÈRE, 2007, p. 61)

Segundo o próprio Pêcheux, em seu artigo Ler o arquivo hoje, é na "relação entre língua como sistema intrinsicamente passível de jogo, e a discursividade como inscrição de efeitos lingüísticos materiais na história" que se "constitui o nó central de um trabalho de leitura do arquivo." (PÊCHEUX, 1997, p.63).

Dessa forma, na leitura do arquivo, a materialidade da língua, não pode ser tomada como algo transparente, que aponta para uma leitura unívoca e inocente dos fatos, como acreditaram, por muito tempo (e, talvez, ainda acreditem e pratiquem essa leitura), literatos e cientistas (cf. PÊCHEUX, 1997). Portanto, segundo Pêcheux, o que era urgente se consagrar "nas práticas diversificadas de trabalhos sobre o arquivo textual" é a existência da "materialidade da língua na discursividade do arquivo". Só assim, o analista de discurso seria capaz de identificar, em seu gesto de leitura do arquivo, "os interesses históricos, políticos e culturais", sem cair nos "riscos redutores do trabalho com a informática." (PÊCHEUX, 1997, p.63). Observamos, portanto, que a informática representava uma "curiosidade", um recurso que se inscrevia no interior de um "pensamento político". Um universo discursivo, aparentemente, logicamente estabilizado, mas que preservava interrogações para Pêcheux, que abria brechas para a desconstrução do fechamento do sentido. Das muitas relações que Pêcheux travou, ao longo dos seus estudos, com diferentes teóricos da linguística, do marxismo, da psicanálise, talvez, segundo Maldidier, sua relação com a informática é sua maior momento que este objeto se inscreve na história é que ele significa e pode ser considerando, portanto, um discurso. Então, as diferentes materialidades linguístico-discursivas que vão surgindo a partir das mudanças sócio-históricas produzem novas discursividades e, por sua vez, outros corpora que merecem um olhar do analista de discurso. 
originalidade. "Ele não queria se servir dela, ele queria a fazer servir." (MALDIDIER, 2003, p.97). E tal afirmação de Maldidier é confirmada pelas próprias palavras de Pêcheux:

nem ceder às facilidades verbais da pura denúncia humanista do "computador", nem se contraidentificar ao campo da informática (o que tornaria a reforçar o projeto desta), mas tomar concretamente partido, no nível dos conceitos e procedimentos, por este trabalho do pensamento em combate com sua própria memória, que caracteriza a leitura-escritura do arquivo, sob sua diferentes modalidades ideológicas e culturais, contra tudo o que tende hoje a apagar este trabalho. Isto supõe também construir procedimentos algoritmos informatizados, traduzindo, tão fielmente quanto possível, a pluralidade dos gestos de leitura que possam ser marcados e reconhecidos no espaço polêmico das leituras de arquivo. (PÊCHEUX, 1997, p.63-64)

A informática, segundo Pêcheux (op. cit), possibilitaria uma leitura "em que o sujeito é ao mesmo tempo despossuído e responsável pelo que lê", abrindo espaço para a construção de máquinas paradoxais. Um sujeito, portanto, que tem a ilusão de liberdade para construir os seus próprios percursos de leitura. Passa-se, assim, das máquinas estruturais para máquinas paradoxais, as quais complexificam/diversificam os processos de leitura e também de escrita. Observamos, a partir desse breve percurso, que a relação da informática com o discurso atravessa a obra de Pêcheux, nunca tomada como um instrumento neutro, mas como parte integrante da própria pesquisa, como um instrumento que permite a apreensão de corpora variados de grande dimensão.

O que, talvez, Pêcheux não imaginava é que a informática hoje nos servisse a tantos e diferentes propósitos. Mais do que instrumento de apreensão/coleta de corpora variados, a informática possibilitou o advento da internet e, com ela, o surgimento de novas materialidades e, por sua vez, novas discursividades. Muitas pesquisas foram realizadas aqui no Brasil durante esses 40 anos de existência da Análise do Discurso, as quais tiveram como objeto de análise desde o discurso político, até o discurso das/sobre as novas tecnologias. Só o espaço virtual, configurado pelos desdobramentos da rede mundial de computadores, o chamado ciberespaço, abriu para os analistas de discurso inúmeras novas possibilidades de materialidades que merecem análise: filmes, vídeos, jornais, revistas, blogs, chats, publicidades etc que circulam na rede e são circunscritas por novas condições de produção.

Ao lado dessas materialidades, novas discursividades, surgidas a partir das novas tecnologias, continuam sendo objeto de análise dos analistas de discurso brasileiros o discurso político, religioso, científico, pedagógico etc. Também há analistas que se interessam pelos discursos orais, "não-oficiais", materialidade esta já prevista por Pêcheux nos seus últimos escritos.

Toda essa diversidade, heterogeneidade de discursos mostra o quanto a teoria pensada por Pêcheux foi profícua, servindo a análises das mais diferentes materialidades, não simplesmente do discurso político, como alguns críticos da teoria insistem em afirmar. Mas, se a $\mathrm{AD}$ não serve só para analisar discursos políticos, como muito bem tem mostrado a nossa prática de analistas aqui no Brasil, o político não cessa de aparecer, está sempre presente atravessando todo e qualquer discurso. A AD, como diz o próprio Pêcheux no seu texto $O$ estranho espelho da Análise do Discurso "parece ter experimentado desde suas origens uma tendência irresistível, na França, a eleger como objeto de estudo os "discursos políticos" (mais frequentemente os de esquerda) para auscultar suas especificidades, alianças e demarcações." (PÊCHEUX, 2009, p. 21 22). Mas essa tendência, continua Pêcheux (2009), tem ela própria uma história: a análise do discurso nasceu sob a forma de um trabalho político e científico especializado, visando a tomar posição em um campo ideologicamente estruturado. 
Portanto, grande parte dos desdobramentos da $\mathrm{AD}$, com a abertura de novos corpora, que produziram, por sua vez, avanços e deslocamentos teóricos foi/está sendo produzido por analistas de discursos brasileiros, que reconhecem na figura da prof. Eni Orlandi um marco fundador desse escopo teórico na lingüística praticada no Brasil nas últimas décadas.

Voltando, outra vez, nosso foco ao surgimento das novas tecnologias da informação, podemos afirmar que, via informática, esse campo tornou-se fértil aos analistas de discurso, que buscam sobretudo na internet muitos objetos em "estado de corpus". É verdade que as noções de texto, leitura, escrita, autoria, sujeito etc sofreram deslocamentos. Mas o aparato teórico-metodológico proposto por Pêcheux continua sustentando nossas bases, enquanto analistas, lançando luz para refletirmos sobre as muitas questões que surgem diante desses novos objetos.

E, para finalizar esse artigo, proponho então que pensemos um pouco sobre uma dessas novas materialidades em "estado de corpus", surgida com o advento da internet, mas ligada a um discurso tradicional - o nosso "velho" e tão conhecido discurso pedagógico. Qual seja: o discurso pedagógico em Ambientes Virtuais de Aprendizagens, os chamados AVAs.

\section{REFLETINDO SOBRE O FUNCIONAMENTO DO DISCURSO PEDAGÓGICO EM AMBIENTES VIRTUAIS DE APRENDIZAGEM}

Para pensarmos no funcionamento desse discurso, pontuo, inicialmente, algumas questões:

1) O discurso pedagógico que circula nos ambientes virtuais de aprendizagem continua sendo autoritário?

2) Que posições sujeito são assumidas pelo professor e pelo aluno? Ou melhor, há lugar para a voz do aluno? Há troca de reversibilidade? De que natureza é a interação nesses ambientes?

3) A imagem que o aluno faz do professor é outra?

Para refletirmos sobre essas questões é preciso, em primeiro lugar, considerar que as condições de produção em que esse discurso pedagógico circula são outras, diferentes da sala de aula presencial. A sala de aula, enquanto espaço físico, com a presença física de professores e alunos, não é mais física, e sim virtual. Assim, o discurso pedagógico não mais é (re)produzido no espaço empírico (Cf. Grigoletto, 2005), no qual o lugar social de professor e aluno estão bem definidos e são determinados pelas relações de poder da escola, enquanto Aparelho Ideológico de Estado. O discurso pedagógico passa a circular, no ensino a distância, em outro espaço: o espaço virtual ${ }^{4}$.

4

Não vou aprofundar aqui essa discussão sobre o espaço virtual, mas estou tomando-o, para efeitos desse artigo, como um espaço caracterizado pelo entrelaçamento das práticas sociais e discursivas, que se inscreve no entremeio do espaço empírico e discursivo (cf. Grigoletto, 2005). Isso porque o virtual configura-se como um espaço onde se materializam diferentes discursividades, desde uma sala de bate-papo até situações mais formais onde há uma individualização do sujeito pelo Estado através de serviços, como os bancários, que hoje realizamos pela internet. Há, como diz Souza (2006), no espaço virtual, a posição de incluídos ou excluídos, conforme o espaço em que o internauta estiver navegando. Em alguns sites institucionais, por exemplo, há solicitação de senhas para navegação, o que resulta numa forma de regulação, de coerção social, afastando-nos da ideia de que na internet, no espaço virtual, não há controle, que "pode tudo". Eis o espaço empírico, que controla, através das relações de poder institucionais, o que pode e deve ser dito do espaço discursivo no espaço virtual. Por isso, o espaço virtual ao mesmo tempo em que abriga diferentes discursividades, ele próprio se constitui num espaço de discursividade, mas não sem a determinação da prática social. Trata-se, no entanto, de um espaço de discursividade com características próprias, com especificidades que não estão presentes em práticas discursivas que acontecem fora da rede. É o caso, por exemplo, da prática discursiva escolar. O espaço virtual constitui-se assim num espaço simbólico, marcado por contradições, por silenciamentos, por múltiplas vozes (algumas anônimas, outras não) que se (con)fundem numa trama de sentidos. 
Considerando então o espaço virtual como o espaço em que o discurso pedagógico, no ensino na modalidade a distância, se inscreve, temos, como já apontamos, outras condições de produção, diferentes daquelas que regulam o discurso pedagógico no presencial.

No discurso pedagógico em ambientes virtuais de aprendizagem, a voz audível do professor, materializada em um texto fugaz por natureza, próprio do ensino presencial, é substituída por um texto escrito, supostamente coerente e linear, no qual a voz do professor se corporifica nos folhados textuais do hipertexto, que se propõem à mediação da aprendizagem. Tal texto é disponibilizado ao aluno na sala de aula virtual, no início de cada disciplina, num só bloco, e torna-se, junto com outros recursos, a materialidade do discurso pedagógico nesse espaço. Com esse deslocamento da fala para escrita, continua sendo o professor a voz do saber e o discurso pedagógico caracterizado como do tipo autoritário? Qual a natureza do hipertexto nesse espaço? Como ele é construído?

Para responder a esses questionamentos, inicio retomando a proposta das tipologias discursivas, apresentadas por Orlandi (2001, p.15), em seu livro A linguagem e seu funcionamento. Baseada no critério do referente e dos participantes do discurso, e tomando como base dois processos de produção de sentidos (a paráfrase e a polissemia) a autora distingue três tipos de discurso: a) o lúdico: a polissemia é aberta e o objeto mantém-se enquanto tal; b) o polêmico: a polissemia é controlada e os participantes procuram dominar o seu referente; c) o autoritário: a polissemia é contida e o referente está "ausente", oculto pelo dizer. Orlandi afirma que o discurso pedagógico é do tipo autoritário em que A (imagem do professor) ensina R (referente) a B (imagem do aluno) em X (escola). Esse esquema de formações imaginárias continua presente no ensino a distância, no entanto, o X ganha um outro status, pois o onde desdobra-se em dois espaços distintos: o empírico, representado pela instituição que propõe o curso, e o virtual, caracterizado pela sala de aula virtual, lugar onde efetivamente se dá o processo de ensino-aprendizagem. O que muda, efetivamente, então, é o material didático (sobretudo sua natureza e modo de disponibilização) e o modo de interlocução professor/aluno. Segundo Orlandi (2001, p.22), o material didático tem o caráter de mediação, mas essa função, no discurso pedagógico tradicional, é apagada e passa de instrumento a objeto. "Enquanto objeto, o material didático anula sua condição de mediador. (...) Como objeto, ele se dá em si mesmo, e o que interessa é saber o material didático." A crítica que a autora está fazendo aqui se refere ao fato de o material didático, muitas vezes, ocupar o próprio lugar do saber, havendo uma sobreposição da voz do material didático sobre a voz do professor. Em outras palavras, o saber do material didático é transmitido ao aluno pela voz do professor, que, por ser a voz do saber (dizer e saber se equivalem), apaga esse saber vindo de outro lugar e o transmite ao aluno como se fosse dele. E, no ensino a distância, qual a função do material didático? É essencial, já que, sem material didático, não há curso. E, embora também ocupe esse lugar de saber, o material didático mantém a função de mediação, já que, diferentemente do que acontece no presencial, essa voz não se sobrepõe à voz do professor, mas é a própria voz do professor, materializada num texto que ele produziu, responsabilizando-se pela sua autoria. Nesse texto, o professor, na função de autor, disponibiliza ao aluno acesso a outras vozes, a outros textos, a outras materialidades, a outras discursividades, construindo um efeito-leitor, através da simulação/da encenação de um possível diálogo com seu aluno. Vejamos alguns exemplos: 


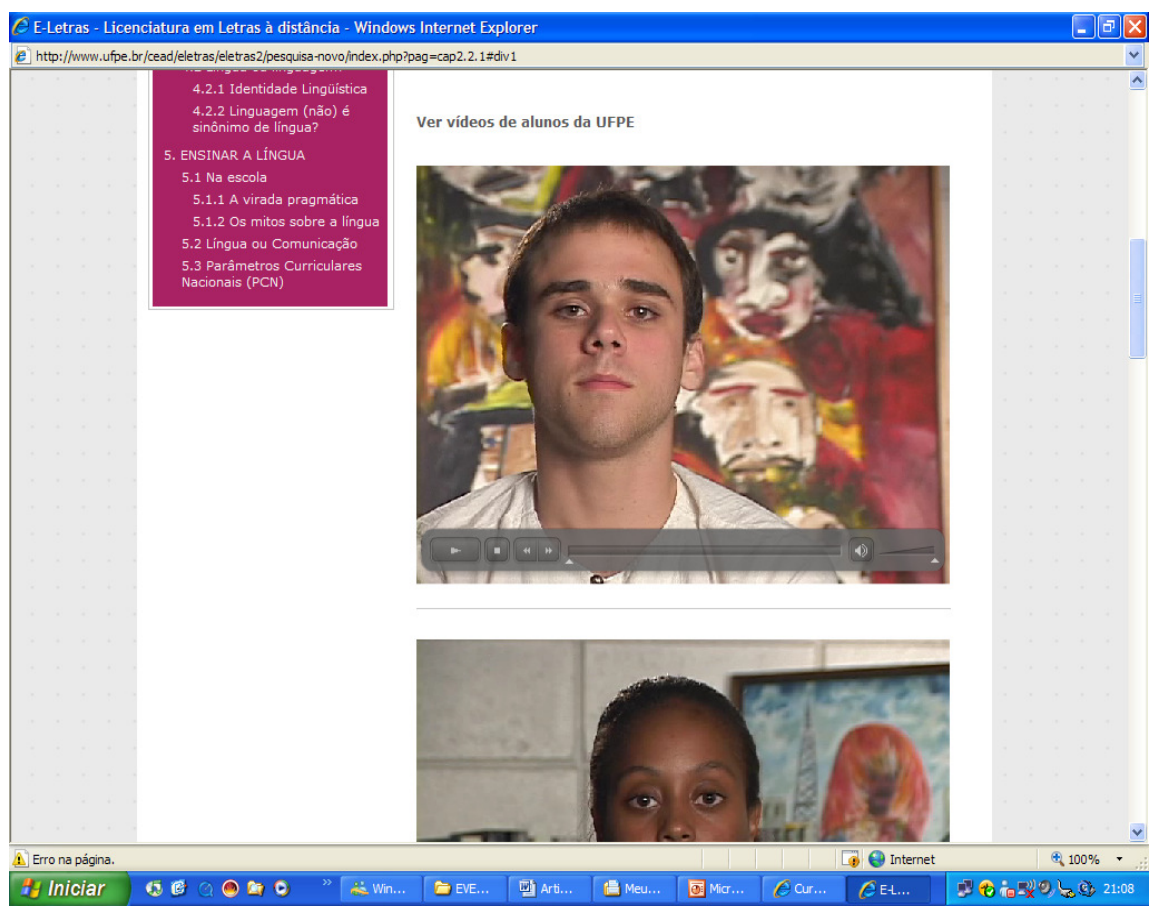

Fig. 1

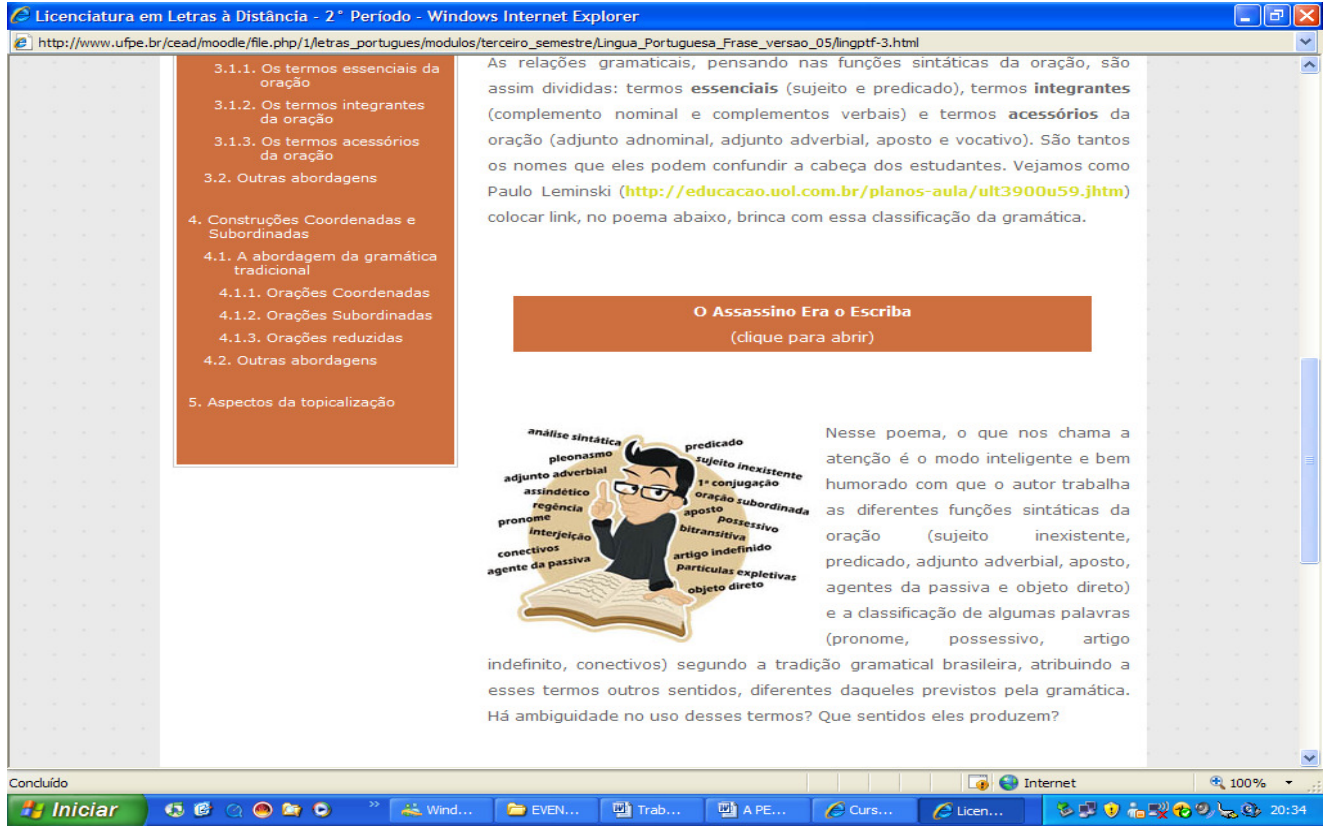

Fig. 2 


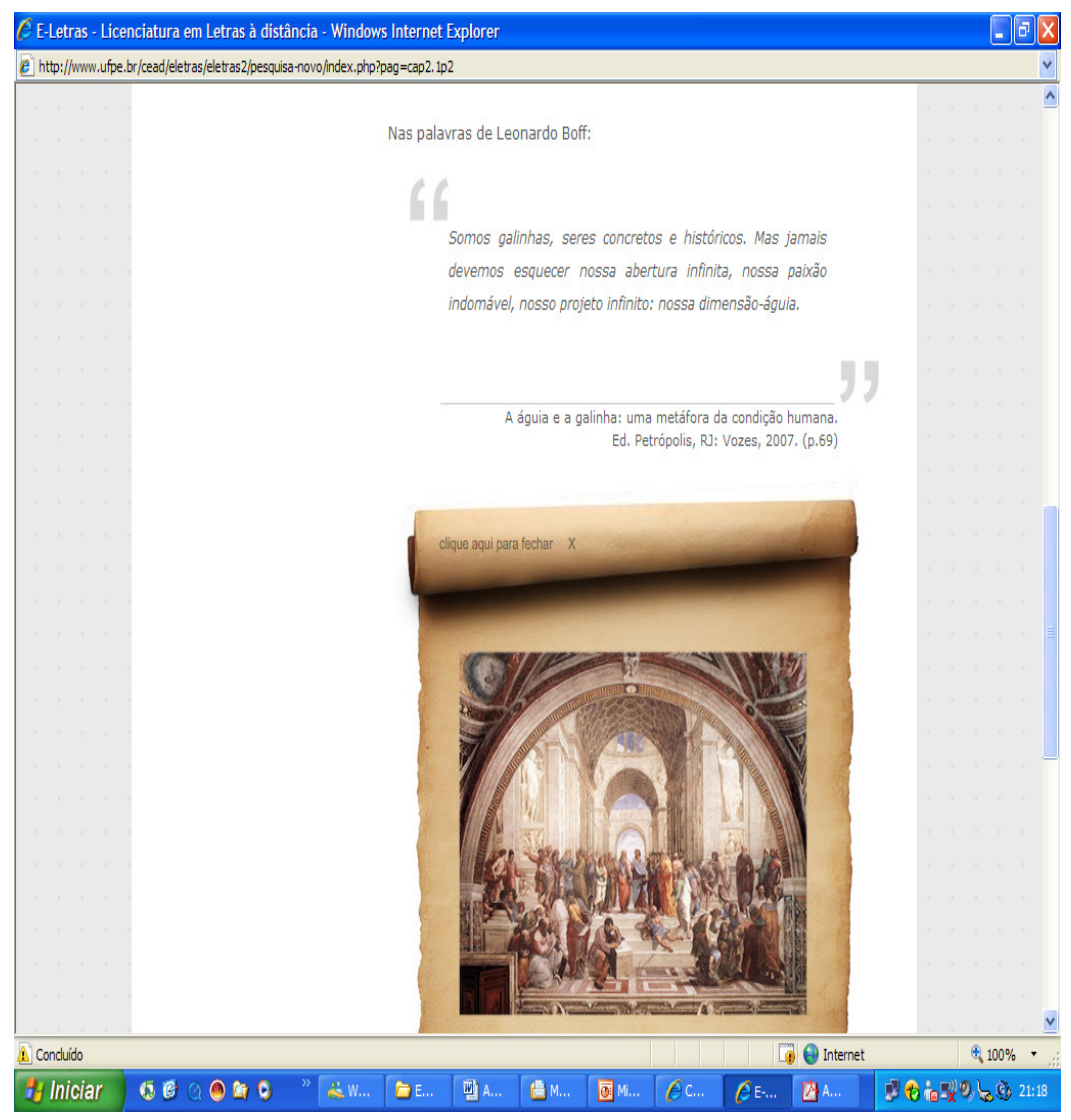

Fig. 3

Observamos, nos três exemplos apresentados, que o discurso pedagógico abre para outras vozes, outras materialidades, simulando, algumas vezes, uma interlocução com o aluno (Há ambiguidade no uso desses termos? Que sentidos eles produzem?- tela 2 ), ordenando outras vezes (clique aqui para abrir- tela 3). No entanto, é preciso observar que esses pontos de deriva são determinados, estão sob o comando da voz do professor que dá a direção de sentidos que o aluno deve seguir. Então se, por um lado, o material didático que, entre outros textos, discursiviza o discurso pedagógico no ensino a distância apresenta a vantagem de abrir a possibilidades (na própria voz do professor) de acesso a outras vozes, o que nem sempre acontece no ensino presencial, ele não apresenta a possibilidade de reformulação (pelo menos enquanto a disciplina estiver no ar), não abrindo espaço para o trabalho do esquecimento $n^{\circ} 1$ do sujeito. Assim, o conteúdo tradicional apresentado aos alunos na sala de aula presencial, de forma oral e complementado pela leitura de textos teóricos na maioria das vezes, transforma-se em hipertexto no Ensino a Distância, e a oralidade é substituída pela escrita. Uma escrita que, como podemos observar nessas telas acima, não carrega o ranço do texto científico, ao mesmo tempo em que incorpora outras materialidades, que têm como função deixar o conteúdo mais atrativo ao aluno, seduzindo-o não só pelo escrito, mas também pelo visual. Portanto, nesse aspecto, o discurso pedagógico continua sendo autoritário, embora encene situações de troca de reversibilidade entre os seus interlocutores. No entanto, se, em relação ao material didático, o discurso pedagógico continua sendo do tipo autoritário, em outros espaços de interlocução, o aluno é interpelado a dizer, a efetuar a troca de reversibilidade. A interdição não está no dizer, mas sim no silenciar. 
Para se legitimar na posição de aluno, é preciso que ele diga. Há a demanda de um efetivo trabalho de subjetivação do sujeito-aluno que deve se dar pela escrita. Ele precisa discursivizar o seu dizer nos fóruns de interação, nas respostas às atividades etc, sendo, portanto, garantido o seu espaço de dizer.

Assim, a leitura e a escrita assumem uma outra dimensão no ensino a distância. Para que haja, efetivamente, processo de aprendizagem, a noção de leitura e escrita como práticas sociais, como lugares de interpretação, de subjetivação dos sujeitos deve sustentar a prática pedagógica desses ambientes, produzindo efeito, significando nos/para os sujeitos envolvidos nesse processo. Como nos diz Freire (2009, p.4), as diferentes vivências nos diferentes espaços dos Ambientes Virtuais de Aprendizagem (AVAs), "demandam diferentes papéis discursivos - leitor de si mesmo, leitor do outro, escrevente, comentador, debatedor, etc -, o que ajuda o professor em formação a conceber a leitura e a escrita para além de uma visão normativa e ortográfica de língua (...)". Gostaria de acrescentar outro papel, além dos apontados pela autora, que, no meu entendimento, é fundamental para o exercício do ensino a distância: a autoria. Diria ainda que esses papeis, além de ajudar o professor em formação (no caso da autora, os alunos), a conceber a leitura e a escrita além de uma visão normativa, também deveriam ajudar o próprio professor conteudista e os tutores presenciais e a distância a tomar a leitura e a escrita numa dimensão social.

É interessante também observar a representação de escrita e leitura que é produzida, sobretudo pelos alunos, nesses espaços, que nos ajudam a entender, por exemplo, os modos de interlocução construídos nos fóruns, bem como o imaginário construído sobre o professor.

Freire, ao refletir sobre o aprendizado online, afirma que esse se dá "à medida que se interage com (o ambiente) e por meio do ambiente com o outro. Assim, o usuário legitima aquela interface (com todos os seus elementos) como uma espécie de "língua" que lhe permite interagir com o computador. Uma "língua" com recursos expressivos, emprestados da sua língua, com funções específicas." (FREIRE, 2009, p.17)

Veja que a autora está falando de uma representação de língua que está associada à interação com o ambiente. Prefiro pensar em uma representação de escrita, que se materializa pela língua, através do ambiente. E elejo a palavra interação para pensar esse movimento do sujeito com a máquina, já que ele exige mesmo do sujeito uma ação, que já é pré-programada, e que permite determinadas ações e exclui outras. Para tratar da "interação" entre os sujeitos envolvidos no processo ensino-aprendizagem a distância (professores, alunos e tutores), vou utilizar o termo interlocução (na falta de um termo mais apropriado), estabelecendo uma relação com a noção proposta por Pêcheux de discurso como "efeito de sentido entre interlocutores". Assim, se o discurso é efeito de sentido entre os interlocutores, o movimento da linguagem enquanto trabalho (cf. Orlandi) produzido por esses sujeitos é o de interlocução.

Souza (2001), ao incorporar na sua prática pedagógica, em uma disciplina do curso de Letras presencial, uma atividade que exigia dos alunos o cumprimento de parte da carga horária da disciplina na rede, assim, refere-se à ideia de interação:

Refiro-me à idéia de interação que não seja mera discussão em que uns têm razão e outros estão errados. (...) Quero atentar, antes de tudo, para um modelo de interatividade que constitua a conversação, forma interativa criadora, já que nela não é o certo ou o errado que importa tal como as mais pueris situações cotidianas e os mais batidos jogos escolares de busca da melhor resposta. (SOUZA, 2001, p.17)

Embora concorde com a observação feita por Souza acerca da interação, prefiro não utilizar esse termo justamente para não remeter à ideia de ação como atividade 
consciente do sujeito, ou ao esquema estímulo-resposta que remetem às teorias cognitivistas. Estou tomando aqui a interlocução como o movimento dos/entre os sujeitos (não apenas dois) que se dá na ordem do intersubjetivo. Intersubjetivo não no sentido benvenistiano, que considera intersubjetividade como única condição para a comunicação humana, ou "como condição humana inerente à linguagem" (FLORES et al, 2009, p.146). Mas intersubjetividade como o movimento que marca a relação entre os sujeitos do discurso, que não está representada pela relação eu-tu, mas marcada por uma subjetividade da linguagem que assujeita o sujeito a determinadas coerções e, por sua vez, a ocupar determinadas posições. Portanto, a subjetividade não está centrada no $e u$, como propunha Benveniste, mas é constitutiva da linguagem. Considerando então a subjetividade enquanto tal, inerente a todo e qualquer discurso, a intersubjetividade marca o modo como na relação com o outro (outro discurso, outro sujeito, outra voz, outro sentido), os interlocutores se subjetivam. Por isso, estou considerando aqui a interlocução como sendo um movimento da ordem do intersubjetivo.

Voltando à questão que pontuei acima sobre a representação da leitura e da escrita, observamos que, quando o aluno não produz esse movimento intersubjetivo na interlocução com o outro, a escrita desse outro (muitas vezes o professor), não significa para ele. O que eu tenho observado também é que, na maioria das vezes, o aluno não se coloca na posição de ouvinte, de leitor do outro, produzindo um movimento de interlocução que, muitas vezes, fica somente na relação eu-tu.

Vejamos, nas duas sequências discursivas abaixo, como o aluno atribui à escrita um papel de poder, transformando-a, ao mesmo tempo, em algo que contribui para a construção de um imaginário positivo acerca da sua posição de aluno (SD1) e que serve para atingir o outro (no caso, o professor - SD2), como se fosse possível não se "mostrar" pela escrita.

SD1 - Olá professora, boa tarde! Seja bem vinda ao nosso curso e espero contribuir muito para com o andamento da disciplina a qual gosto muito. Abraços. (terçafeira, 9 março 2010 14:35)

SD2 - Professora, eu não estou conseguindo visualizar esse texto: "Los Cromosomas del Idioma Español". Onde é que está isso heim? Ou então eu não estou conseguindo é entender a atividade! Pelo amor de Deus! (sábado, 20 de março de 2010, 22:43)

Parece-me, numa análise rápida dessas sequências, que, a partir de uma representação de língua escrita, o aluno constrói um imaginário sobre o professor. Assim, na tentativa de agradar a professora (SD1), o aluno constrói um discurso que, no seu imaginário, é o correto, o que usa a língua padrão. No entanto, na tentativa de controlar o seu dizer, torna o seu discurso artificial, produzindo equívocos ( $\mathrm{para} \mathrm{com} / \mathrm{a}$ qual). Já, na segunda sequência, quando constrói um outro imaginário da professora (de quem não atende as suas necessidades), torna-se "grosseiro" (Onde é que está isso heim? Pelo amor de Deus!), agredindo-a pela escrita, situação que, possivelmente, não ocorreria no presencial, na face-a-face. Assim, a escrita funciona como uma espécie de espelho que ora mostra, ora mascara sua imagem de aluno.

\section{PRODUZINDO UM EFEITO DE CONCLUSÃO}

Observamos, pelo percurso realizado nesse artigo, o quanto o objeto de estudo da AD - o discurso - pensado por Pêcheux continua sustentando discussões sobre as já 
consagradas práticas discursivas, mas também suscitando novas reflexões sobre práticas discursivas, ou melhor, materialidades discursivas mais recentes.

Ao apresentar o percurso trilhado pelo próprio Pêcheux, flagramos como ele próprio concebia o objeto discurso como constitutivamente heterogêneo, apontando para outras materialidades, outros corpora que poderiam servir de objeto de análise para os analistas de discurso.

Entre esses outros objetos de análise, entre essas materialidades discursivas mais recentes podemos situar o discurso pedagógico produzido em ambientes virtuais de aprendizagem. Nesse discurso, que é uma espécie de espelho (apropriando-me da metáfora utilizada por Pêcheux) do discurso pedagógico tradicional, a autoridade continua representada pela voz do professor por meio do texto escrito onde ele disponibiliza o "conteúdo" da disciplina, bem como por meio das orientações, correções etc que o professor realiza nos diferentes espaços de interlocução da sala de aula virtual. Já, o aluno continua sendo aquele que está ali para aprender, mas a legitimação do seu lugar passa por um processo diferente do ensino presencial. Exige-se do aluno mais autonomia, e seu espaço de dizer está garantido, já que é o que o legitima nessa posição.

É preciso pontuar, a partir dessas considerações, que todo o funcionamento, o movimento desse discurso é atravessado pela prática da escrita que, como vimos, assume uma outra dimensão no ensino a distância. Dimensão essa que ainda precisa ser melhor analisada, explorada, mas isso já é trabalho para um outro artigo...

Então, para produzir o necessário efeito de fechamento desse artigo, retomo as palavras de Pêcheux que utilizei para a epígrafe desse texto: "Já era hora de começar a quebrar os espelhos". Que nós, analistas de discurso, continuemos a quebrar os espelhos de nossas práticas e objetos, não nos tornando cegos em relação à história, nem surdos em relação à língua, trilhando assim o caminho deixado aberto por Pêcheux (nossa sempre presença/ausente).

\section{BIBLIOGRAFIA}

FLORES, Valdir et alii. Dicionário de lingüística da enunciação. São Paulo: Editora Contexto, 2009.

FREIRE, Fernanda. Linguagem, tecnologia, conhecimento e suas relações no contexto de formação continuada de professores. [online]. RUA, Campinas, $\mathrm{n}^{\circ}$ 15, v. 2, 2009. Disponível em: www.labeurb.unicamp.br/rual. Acesso em: 23 mar. 2010.

GRIGOLETTO, Evandra. $O$ discurso de divulgação científica: um espaço discursivo intervalar. Tese de doutorado. Porto Alegre: Instituto de Letras da UFRGS, 2005.

MALDIDIER, Denise. A inquietação do discurso: (Re)ler Michel Pêcheux hoje. Trad. de Eni P. Orlandi. Campinas, SP: Pontes, 2003.

MAZIÈRE, Francine. A análise do discurso: história e práticas. Trad. de Marcos Marcionilo. São Paulo: Parábola Editorial, 2007.

ORLANDI, Eni. A linguagem e seu funcionamento: as formas do discurso. $4^{\mathrm{a}}$ ed., Campinas: Pontes, 2001.

PÊCHEUX, Michel. Ler o arquivo hoje. Trad. de Maria das Graças Lopes Morin do Amaral. In: ORLANDI, E. P. (org.) Gestos de leitura: da história no discurso. $2^{\text {a }}$ ed., Campinas, SP: Editora da Unicamp, 1997, p. 55 - 64. 
Análise automática do discurso (AAD-69). In: GADET, F. \& HAK, T. (Orgs.) Por uma análise automática do discurso: uma introdução à obra de Michel Pêcheux. $3^{\mathrm{a}}$ ed., Campinas, SP: Editora da Unicamp, 1997, p. 61 - 161.

. A análise de discurso: três épocas (1983). In: GADET, F. \& HAK, T. (Orgs.) Por uma análise automática do discurso: uma introdução à obra de Michel Pêcheux. $3^{\text {a }}$ ed., Campinas, SP: Editora da Unicamp, 1997, p. 311 - 318.

. O estranho espelho da Análise do Discurso (prefácio). In: COURTINE, J.J. Análise do discurso político: o discurso comunista endereçado aos cristãos. São Carlos, SP: EDUFSCAR, 2009, p. 21 - 26.

SOUZA, Pedro de. Aprender fora de si: experimento de ensino virtual em análise do discurso. In: CABRAL, L. G; SOUZA, P. de; LOPES, R. V.; PAGOTTO, E. G. (orgs.) Lingüística e ensino: novas tecnologias. Blumenau: Nova Letra, 2001, p. 15 - 40. 